\title{
Emission and vibration characteristics of Niger seed oil biodiesel fueled diesel engine
}

\author{
S. Jaikumar ${ }^{1 *}$, S. K. Bhatti², V. Srinivas ${ }^{1}$ \\ ${ }^{1}$ Department of Mechanical Engineering, GITAM, Visakhapatnam, India, 530045. \\ Phone: +919492804934, \\ *Email: sagari.jaikumar1@gmail.com \\ ${ }^{2}$ Department of Mechanical Engineering, Andhra University, \\ Visakhapatnam, India, 530003.
}

\begin{abstract}
The present investigation dwells the experimental investigation for the assessment of emission, vibration, and noise parameters of single-cylinder, DI diesel engine functioning through the blends of conventional diesel and Niger seed oil methyl ester (NSOME) at different engine operating loads namely $25 \%, 50 \%, 75 \%$, and $100 \%$ at a constant speed. The carbon monoxide (CO), unburnt hydrocarbons (UHC), and smoke opacity emissions have come down significantly for all the blends of NSOME namely B10, B20, and B40 while the $\mathrm{NO}_{\mathrm{x}}$ increased marginally. Besides, the vibration and noise extremity of the engine was lowered while operating with biodiesel blends as compared to conventional diesel. B20 has specified a significant reduction in emission, vibration, and noise too at all the loads range from minimum to maximum. At maximum load condition the $\mathrm{CO}, \mathrm{UHC}$, smoke opacity, root mean square (RMS) velocity, and RMS noise of B20 have reduced by $93.9 \%, 37.87 \%$, $5.54 \%, 45.78 \%$, and $26.15 \%$ respectively even as the $\mathrm{NO}_{\mathrm{x}}$ was increased by $12.76 \%$ compared to standard.
\end{abstract}

Keywords: Noise; Niger seed oil methyl ester; emissions; root mean square.

\section{INTRODUCTION}

In the present existence, the researchers have attempted repeatedly to find numerous new renewable resources associated with pollution concern, limited relieve in use, the growing shortage of fuel, and quick diminution of fossil fuels. Biodiesel is the most selected option for the standard diesel owing to less carbon content and its environmental benefits [1]. Biodiesel is an alternative fuel extracted from different vegetable oils and capable of use in compression ignition engines by blending appropriately with standard diesel. On account of durability and high combustion efficiency, the CI (compression ignition) engines are broadly used in the farming field in addition to the industry for mobile and immobile applications. Although, the consumers are strongly influenced by the exhaust emissions, noise, and vibrations developing from the burning of fuel powered-engines [2-4].

Biodiesel and their blends with conventional diesel cloud strongly reduce the exhaust emissions like $\mathrm{CO}$, unburned hydrocarbon (UHC) and smoke opacity on account of superior combustion and amount of oxygen presence [5]. The sound and vibrations produced from the 
IC engine are the major drawbacks and have harmful effects on the human body. The primary source of engine vibration is due to the rotational and reciprocating components of the engine. An additional lead source of vibration and hence noise in the CI engine is owing to the efficient burning of fuel which extensively depends on the type of fuel and fuel injectors used $[6,7]$. The noise levels could be estimated by converting the vibration signals employing Fast Fourier Transformation (FFT), Wavelet transforms (WT), and Short-time Fourier Transform (SFFT) analysis. Since the noise measurement in the combustion chamber is a tough task [8]. The vibration amplitude is estimated and compared to in terms of root mean square (RMS) since it confers the time history which is proportional to the vibration signature [9]. The vibration and noise could decrease while the engine is operating with biodiesel and their blends on account of better combustion efficiency [10,11].

Numerous authors have performed different researches on emission characteristics and very few investigations were gone through in the field of engine vibrations and noise. Jaikumar et al. [12] experimented with variable compression ratio (VCR) diesel engine using Niger seed oil biodiesel blends. Form their results, the combustion parameters were improved and the emissions of CO, UHC, and smoke opacity were decreased while the $\mathrm{NO}_{\mathrm{x}}$ was noticed higher than conventional diesel. Vijay et al. [13] experimentally investigated on blends of mango seed oil methyl ester and diesel. The results have revealed that the notable reduction in emissions was noticed apart from $\mathrm{NO}_{x}$. Senthur et al. [14] explored the emission parameters of used cooking oil biodiesel on CI engine and reported that a momentous diminution in $\mathrm{CO}$ and $\mathrm{UHC}$ were observed with a minor rise in NOx. Some researchers have attempted experimental studies on vibration and noise analysis. How et al. [15] conducted tests on coconut methyl ester and diesel blends. RMS acceleration (vibration) was observed to be decreased by $13.7 \%$ with B50. Zhi et al. [16] investigated vibration analysis and performance of biodiesel derived from Calophylluminophyllum. It was concluded that the B20 blend exhibited lower vibrations than standard diesel. The effect of different engine speeds operating with biodiesel blends was investigated by Heidaryet et al. [17]. They accomplished that the B10 and B15 blends produced higher vibrations and it was found that most of the vibrations are in engine piston direction. Uludamar et al. [18] studied the influence of different biodiesel blends on vibration and noise characteristics of the CI engine. The results concluded that the engine vibration and noise levels were minimized with raise in blend ratio. Zhen et al. [19] have investigated the noise signature of four-cylinder turbocharged CI engine for biodiesel blends B50 and B100 which revealed that the noise levels of biodiesel and their blends were marginally greater. Further, the noise levels have increased with increase in blend ratio from B50 and B100. Sanjid et al. [20] compared the diesel engine noise running with palm and jatropha biodiesel. The results concluded that the noise levels have reduced significantly than the standard diesel. Jaikumar et al. [21] examined the vibration and noise constraints of Niger seed oil biodiesel and hydrogen in dual fuel operation by varying different compression ratios. Their results revealed that the vibrations and noise were decreased with biodiesel blends and hydrogen-enriched blend as well.

Based on the existing literature, more than a few investigations have been carried on the exhaust emission parameters. Besides, fewer research studies have been carried out on vibration and noise and thus still there is some gap in detailed investigations in terms of varying engine loads. In the present investigation, the emission, vibration, and noise parameters were assessed by varying dissimilar load conditions. Hence, the load variation 
from lower load to higher load condition of assessing these operating parameters with Niger seed oil methyl ester (NSOME) blends has been centered as a novel attempt.

\section{MATERIALS AND METHODS}

NSOME has been prepared by transesterification technique [12] and three different blends were prepared by mixing with diesel. The test fuels are designated as diesel, B10, B20, and B40 by blending NSOME (B100) with diesel at different proportions namely $0 \%, 10 \%, 20 \%$, and $40 \%$ respectively by volume [12]. The physic-chemical properties of NSOME and their blends were tested and presented in the Table1.

Table 4. A Thermo-physical property of diesel and diesel - NSOME blends.

\begin{tabular}{|c|c|c|c|c|c|c|c|}
\hline Fuel property & $\begin{array}{l}\text { Method } \\
\text { ASTM }\end{array}$ & $\begin{array}{l}\text { ASTM } \\
\text { Range }\end{array}$ & B100 & B40 & B20 & B10 & Diesel \\
\hline $\begin{array}{l}\text { Relative Density at } \\
15^{\circ} \mathrm{C}\left(\mathrm{kg} / \mathrm{m}^{3}\right)\end{array}$ & D-1298 & $860-900$ & 887.9 & 883 & 877 & 872 & 831 \\
\hline Heating value $(\mathrm{kJ} / \mathrm{kg})$ & D-4809 & 42,000 & $\begin{array}{c}41,30 \\
0\end{array}$ & $\begin{array}{c}41,42 \\
0\end{array}$ & $\begin{array}{c}41,63 \\
0\end{array}$ & $\begin{array}{c}41,90 \\
0\end{array}$ & $\begin{array}{c}43,80 \\
0\end{array}$ \\
\hline $\begin{array}{l}\text { Fuel quality (Cetane } \\
\text { Number) }\end{array}$ & D-976 & 47 (min.) & 59 & 58 & 57 & 54 & 50 \\
\hline Copper Corrosion & D-130 & $1(\max )$ & $1 \mathrm{a}$ & $1 \mathrm{a}$ & $1 \mathrm{a}$ & $1 \mathrm{a}$ & $1 \mathrm{a}$ \\
\hline $\begin{array}{l}\text { Kinematic Viscosity } \\
\text { at } 40^{\circ} \mathrm{C} \\
\text { (Cts) }\end{array}$ & D-445 & $2.5-6$ & 4.2 & 4.07 & 3.94 & 3.86 & 2.6 \\
\hline Cloud point $\left({ }^{\circ} \mathrm{C}\right)$ & D-97 & $6(\max )$. & 3 & 3 & 3 & 3 & -2 \\
\hline Flashpoint $\left({ }^{\circ} \mathrm{C}\right)$ & D-92 & 130 (min.) & 157 & 155 & 148 & 131 & 51 \\
\hline
\end{tabular}

Figure 1 depicts the representation of a four-stroke single cylinder VCR diesel engine and the engine specifications were tabulated in Table 2. In the present investigation, the engine is coupled through the dynamometer in conjunction with the load controller. On one side of the engine, the fuel tank is connected with a fuel flow sensor. Further on the other side, the exhaust emissions measurement device (MARS smoke meter and MARS gas analyzer) is connected. The engine is also linked to a Laser Doppler Vibrometer (LDV) to measure the vibration magnitude at a fixed point by detecting the signals through a laser beam. These signals were captured from USB based vibrosoft-20 software and FFT analyzer. The detailed specifications of LDV are presented in Table 4. The sensors and LDV are coupled to a computer via an analogue to digital converter which displayed the results. The vibrations and noise levels are recorded at engine head which accounts for the bulk of vibrations generated. Accuracy of the instruments used in this study is shown in Table 3. 


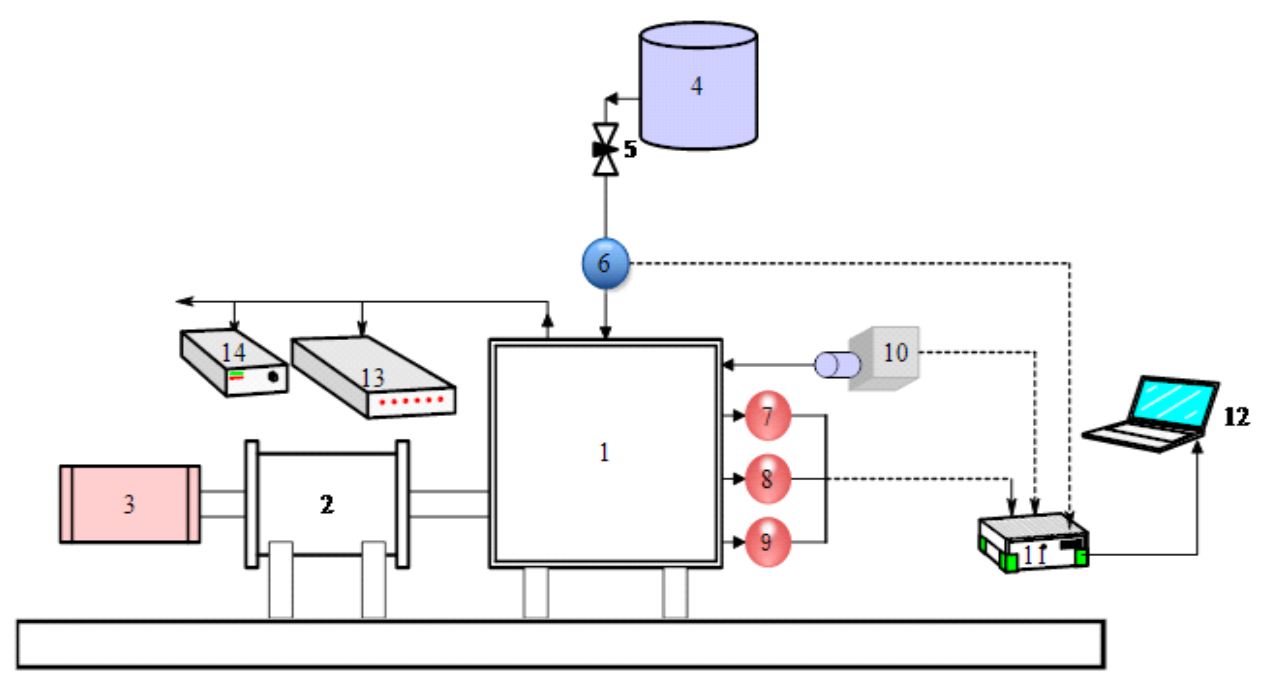
1. Engine
2. Dynamometer
3. Load control
4. Fuel tank
5. Control valve

6. Fuel flow sensor

11. $\mathrm{ADC}$

7. Pressure sensor

12. Computer

8. Speed sensor

13. MARS gas analyzer

9. Crank angle encoder

14. MARS smoke meter

10. LDV

Figure 1. Schematic of the engine test rig.

Table 2. Experimental test rig specification.

\begin{tabular}{cc}
\hline Parameter & Description \\
\hline Type & TAF-1 \\
Cylinders & 1 \\
Cylinder bore & $87.5 \mathrm{~mm}$ \\
Compression ratio & 17.5 \\
Length of stroke & $110 \mathrm{~mm}$ \\
Fuel Injection pressure & $200 \mathrm{bar}$ \\
Maximum power & $3.5 \mathrm{~kW}$ \\
Rotational speed & $1500 \mathrm{rpm}$ \\
5-gas analyzer make & MARS \\
Smoke meter make & MARS \\
\hline
\end{tabular}

The experimentation was carried at four different load conditions of $25 \%, 50 \%, 75 \%$, and $100 \%$ at a constant speed of $1500 \mathrm{rpm}$. At every load, the emissions parameters were measured with the help of 5-gas analyzer and smoke meter respectively. Furthermore, the vibration signals were captured and noise data has been mapped using FFT. For vibration and noise analysis, FFT was used. The programs were furnished in vibrosoft-20 software for 
vibration analysis and origin software was used for noise analysis. In origin software the signals were converted into noise in decibels $(\mathrm{dB}(\mathrm{A}))$ and also RMS analysis was used to compare the arbitrary wave vibration amplitude values. The experiments were repeated thrice and the mean values were presented in the graphs. RMS is characterized for comparing vibrations at different conditions. The mean values of total velocity in RMS were compared. The following Equation. (1) is used to calculate RMS velocity.

Table 3. Accuracy of measurements.

\begin{tabular}{ll}
\hline Parameter & Accuracy \\
\hline Load & $\pm 0.2 \mathrm{~kg}$ \\
Speed & $\pm 30 \mathrm{rpm}$ \\
Temperature & $\pm 1 \%$ \\
Piezo sensor & $\pm 0.1 \%$ \\
Crank angle & $\pm 0.2 \%$ \\
CO & $\pm 0.001 \%$ \\
UHC & $\pm 1 \mathrm{ppm}$ \\
NOx & $\pm 1 \mathrm{ppm}$ \\
Smoke & $\pm 0.1 \%$ \\
\hline
\end{tabular}

Table 4. Practical specifications of LDV.

\begin{tabular}{ll}
\hline Parameter & Description \\
\hline Vibrometer type & PDV-100 Portable Digital Vibrometer \\
Software & Vibrosoft-20 \\
Operational distance (meters) & $0.2-30$ \\
Range of Noncontact velocity $(\mathbf{k H z})$ & $0-20$ \\
Connection & USB based, dual-channel \\
\hline & $V_{r m s}=\left[\frac{1}{n} \sum_{k=1}^{n} V^{2}(t)\right]^{1 / 2}$
\end{tabular}

where $V_{r m s}=$ RMS velocity, $n=$ Number of readings during a time period, $V(t)=$ Velocity concerning time.

FFT converts a signal commencing the time domain to the frequency domain and vice versa. For a given data set of $y(k)$ with $n$ number of data samples, the FFT can be calculated using Equation. (2).

$$
y(k)=\left[\sum_{j=1}^{n} y(j) \omega_{n}^{(j-1)(k-1)}\right]
$$

where $\omega_{n}=e^{(-2 \pi i) / n}=$ Angular velocity. 


\section{RESULTS AND DISCUSSIONS}

\section{Emission characteristics}

The emission characteristics namely carbon monoxide (CO), unburnt hydrocarbons (UHC), smoke opacity, and nitrogen oxides $\left(\mathrm{NO}_{\mathrm{x}}\right)$ were presented at different engine loads and different blends of NSOME.

Carbon monoxide ( $\mathrm{CO})$

Figure 2 depicts the change in $\mathrm{CO}$ emissions of different experimental test fuel blends at diverse load conditions.

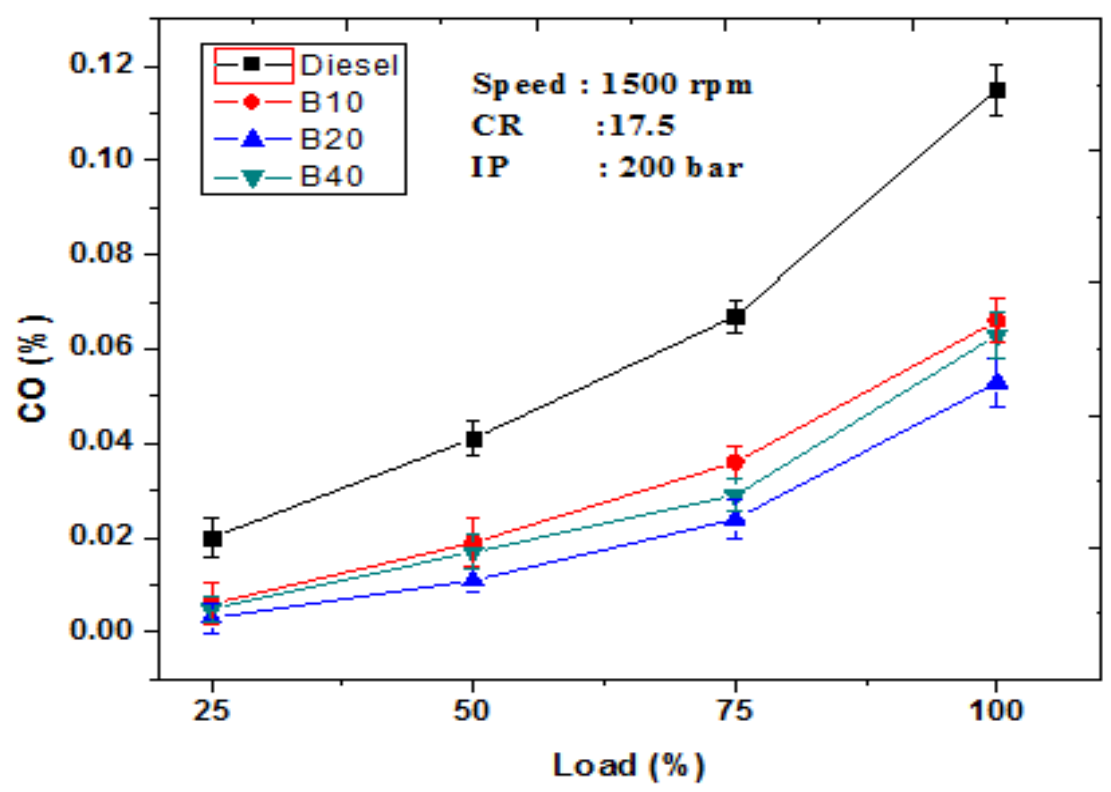

Figure 2. Carbon monoxide emissions.

CO emissions were observed elevated from lower load to higher loads regardless of experimental test fuel blends. The reason intended for this was owing to the richer air-fuel ratio and the reduction in oxidation at upper load condition [13]. Further, a notable fall in CO levels was noticed with NSOME blends. This lessening was in consequence of more amount of oxygen there in the biodiesel than conventional diesel which leads to superior combustion $[12,22]$. The $\mathrm{CO}$ emissions were $115 \%, 0.066 \%, 0.053 \%$, and $0.063 \%$ respectively for diesel, B10, B20, and B40 at full load. Among the leftover test fuels used, the B20 has specified lower $\mathrm{CO}$ emissions.

Unburnt hydrocarbons (UHC)

The disparity of UHC emissions with load was manifested in Figure 3. The rising trend of UHC emissions was observed from lower loads to maximum load condition. The foremost cause for attaining lofty UHC emissions at maximum load was on account of more amount of fuel supply to maintain a constant output power for a given quantity of air. As a result, this makes the wealthier air-fuel mixture and results in higher UHC emissions [5]. The identical trend was continued for all the experimental test fuels. It was noticed that the NSOME blends 
have far lower UHC emissions compared to diesel on account of superior combustion efficiency which was owing to greater cetane number and more oxygen existence in the biodiesel $[12,23]$. Further, the B20 has given least UHC emissions at all the load conditions as compared to other fuels in scrutiny. The emissions of UHC at maximum load were about 140 ppm, 130 ppm, 90 ppm, and 115 ppm, respectively in favor of standard diesel, B10, B20, and B40.

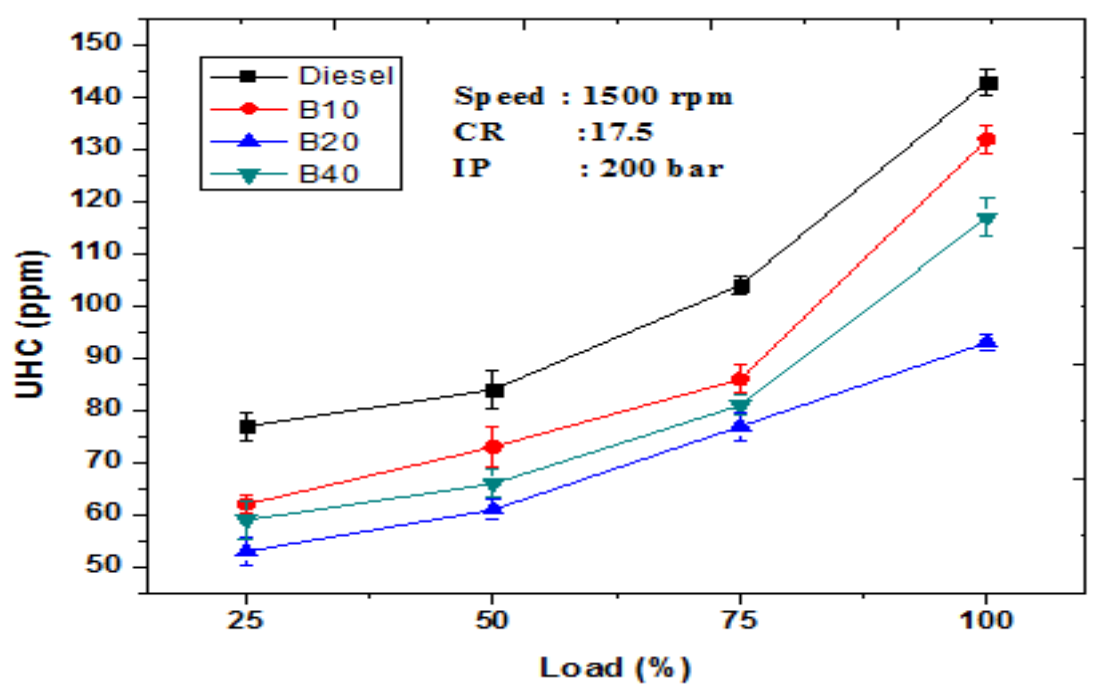

Figure 3.Unburnt hydrocarbons under different loads.

Smoke opacity

Figure 4 portrays the variation of smoke opacity against different loads. The smoke opacity primarily controlled by the type of fuel used and the air-fuel ratio. It was perceived that the smoke opacity for the blends of NSOME was lowered than conventional diesel. This was attributable to oxygen dominance and better fuel quality in NSOME blends.

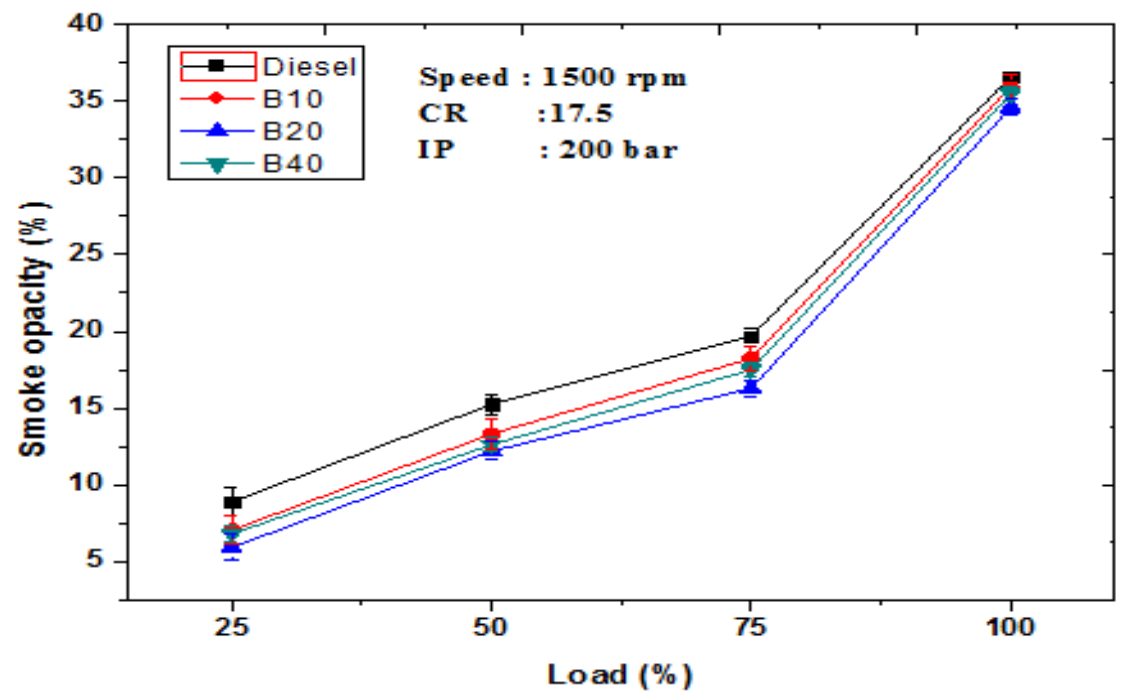

Figure 4. Smoke opacity under different loads. 
Further, the smoke opacity was enhanced from lesser load to the utmost load despite all the fuel blends [24]. This was due to lesser oxidation at maximum load condition owing to the greater amount of fuel injected at a particular supply of air. Therefore, the smoke opacity increased at higher loads. The smoke opacity at maximum load was noticed as $36.34 \%, 35.92 \%, 34.58 \%$, and $35.49 \%$ respectively meant for conventional diesel, B10, B20, and B40. Of all test fuels under scrutiny, B20 has noticed lower smoke opacity with all the load conditions.

Nitrogen Oxides $\left(\mathrm{NO}_{x}\right)$

The emission of NOx at dissimilar loads was depicted in Figure 5. It was scrutinized that the $\mathrm{NO}_{\mathrm{x}}$ was augmented for B10, B20, and B40 than conventional diesel. The corresponding $\mathrm{NO}_{\mathrm{x}}$ emission values were about $698 \mathrm{ppm}, 855 \mathrm{ppm}, 856 \mathrm{ppm}$, and $826 \mathrm{ppm}$ correspondingly at maximum load. The possible reason intended for this surge in $\mathrm{NO}_{\mathrm{x}}$ was on account more oxygen availability and greater temperature of exhaust gas [12, 22].

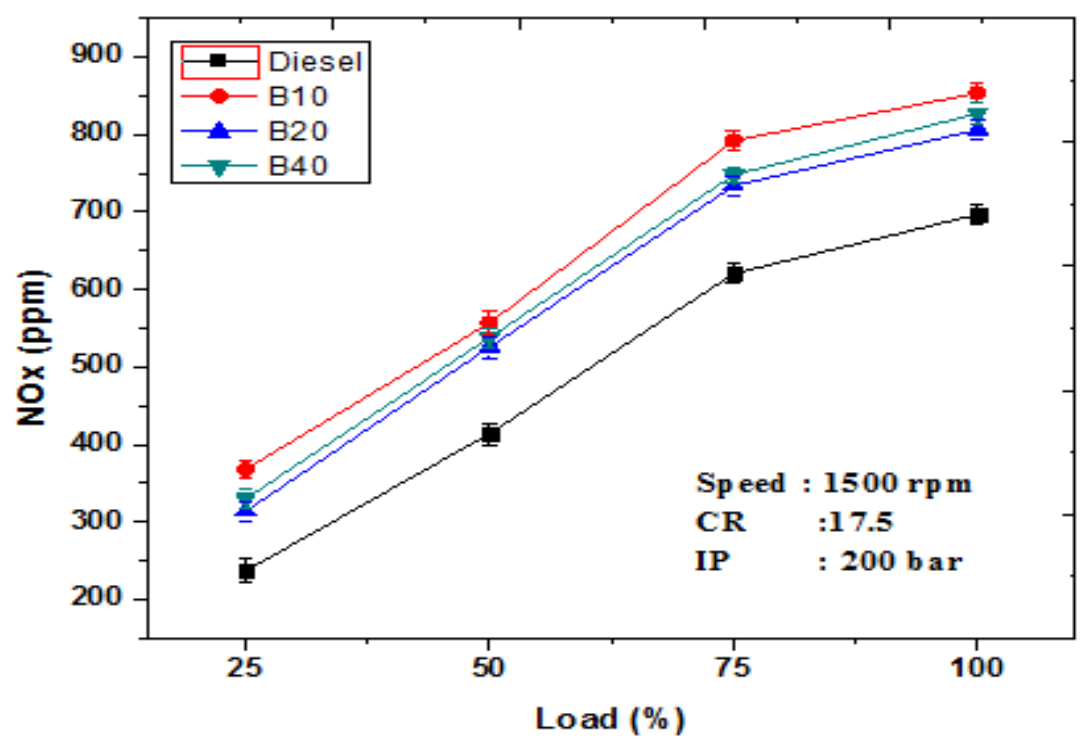

Figure 5. $\mathrm{NO}_{\mathrm{x}}$ emissions under different loads.

Further, the $\mathrm{NO}_{\mathrm{x}}$ has observed a rising trend towards increasing load irrespective of all the test fuels. The standard diesel has perceived lower NOx emissions than NSOME blends.

\section{Vibration and noise characteristics}

The vibration and noise assessment of NSOME and their blends are studied at different loads. The vibration magnitude discussed in terms of velocity $(\mathrm{m} / \mathrm{s})$ and the noise levels were presented in terms of sound pressure levels $\mathrm{dB}(\mathrm{A})$. The variation in RMS velocity with time was shown at maximum load and the RMS velocity at all the loads was also presented.

RMS velocity

The time variation in vibration of different test fuels blends was depicted in Figure 6 and the RMS velocity variation relating to load was presented in Figure 7. It was noticed that the vibration levels of B10, B20, and B40 were lower whereas for diesel it was noticed higher 
range. Since the NSOME blends have improved cetane number and superior oxygen quantity $[12,25]$. Therefore, the combustion superiority attained for NSOME blends and consequently the tendency of knocking reduced. Since the major source of vibration developing from the engine was on account of knocking which was produced in consequence of inappropriate combustion $[12,21]$.

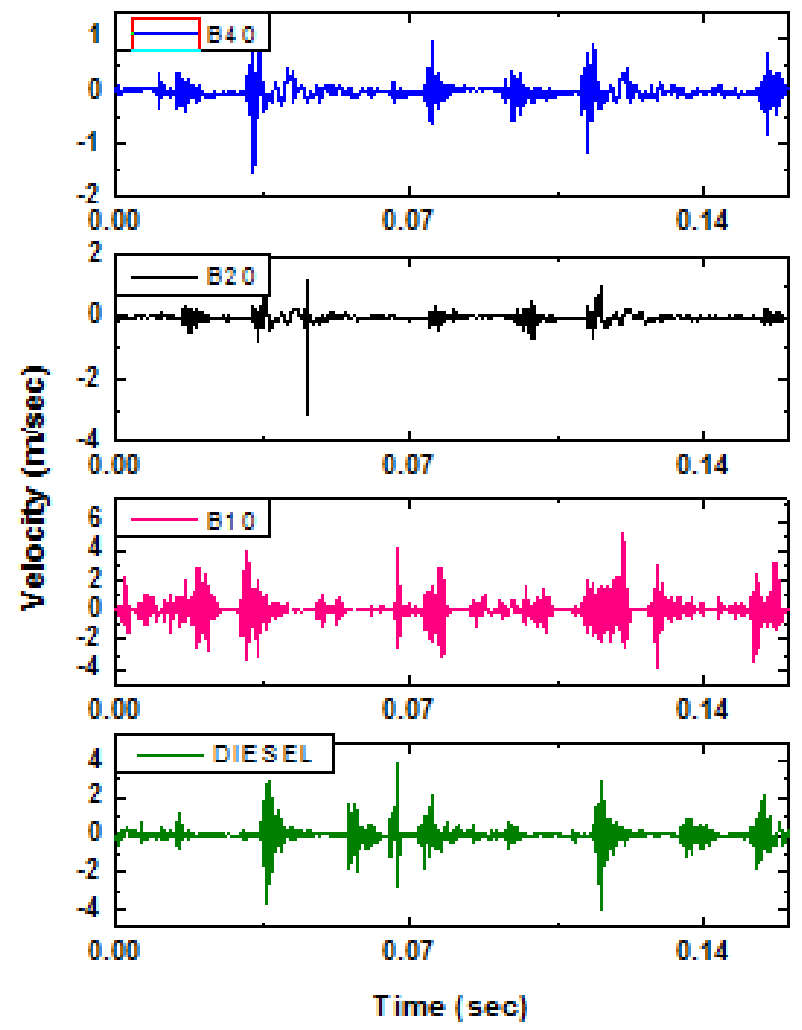

Figure 6.Variation in velocity with time at maximum load.

In addition, the vibration intensity was increased at upper loads and attained maximum at full load as depicted in Figure 7. This was on account of enhanced rate of combustion that produced large thrust on the piston which results in higher vibrations at higher load condition [21]. The similar growing trend was observed in favor of all the test fuels regarding load and the minimum vibration intensity was observed with B20 than remaining fuel blends. RMS velocity on behalf of diesel, B10, B20, and B40 were in the order of $0.49117 \mathrm{~m} / \mathrm{s}, 0.38483 \mathrm{~m} / \mathrm{s}, 0.31499 \mathrm{~m} / \mathrm{s}$, and $0.35571 \mathrm{~m} / \mathrm{s}$ respectively at maximum load. 


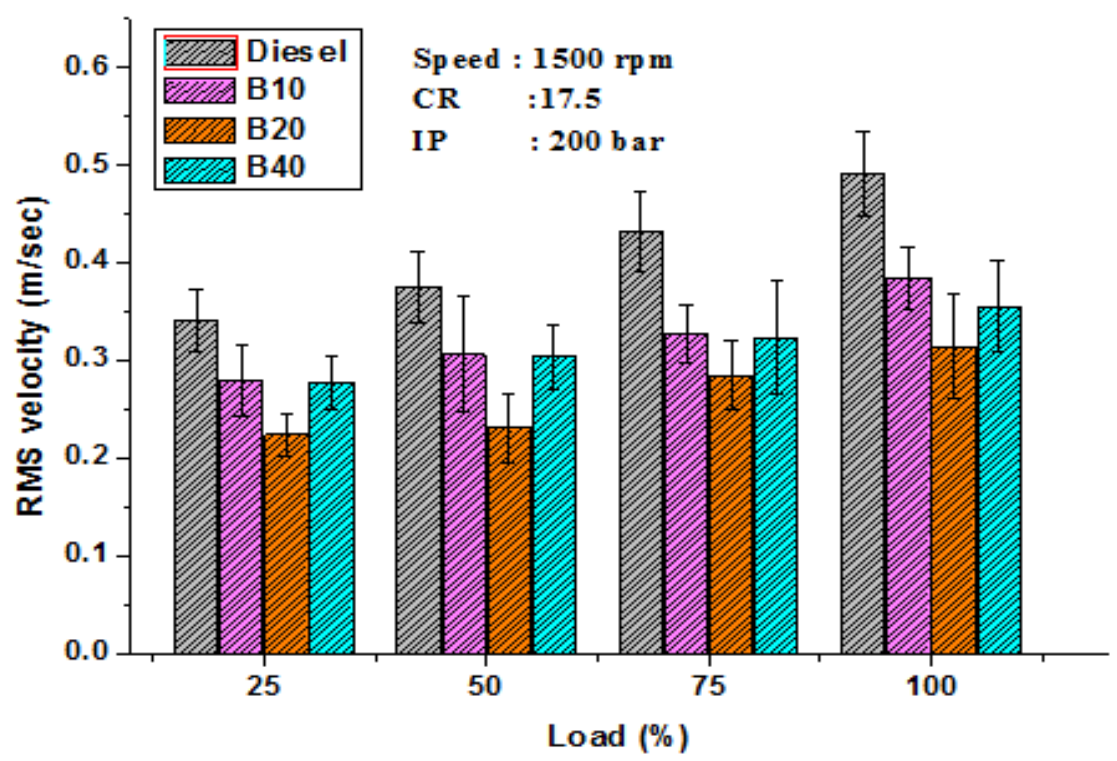

Figure 7. RMS velocity at different loads.

RMS noise

Figure 8 depicts the noise signature of different test fuel blends and the RMS noise at different loads was depicted in Figure 9.

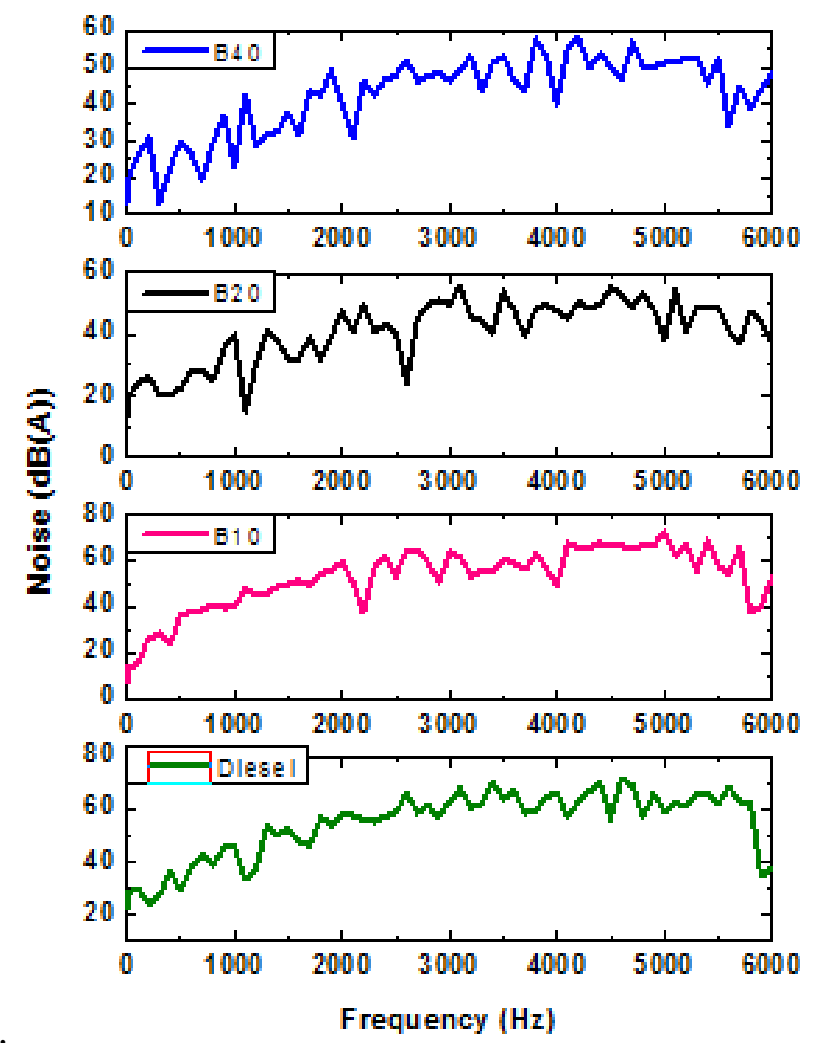

Figure 8. Variation of noise with frequency at maximum load. 
It was identified that the noise levels of B10, B20, and B40 were originated inferior to conventional diesel. This was mainly due to the higher efficiency of combustion as a result of higher cetane number [12]. As the vibration and noise influenced by knocking and thus the engine knocking reduced with this improved combustion [21,26]. Further, the noise was noticed higher at increasing load condition on behalf of all the fuels and the better reduction in noise level was exhibited by B20 at all the load conditions.

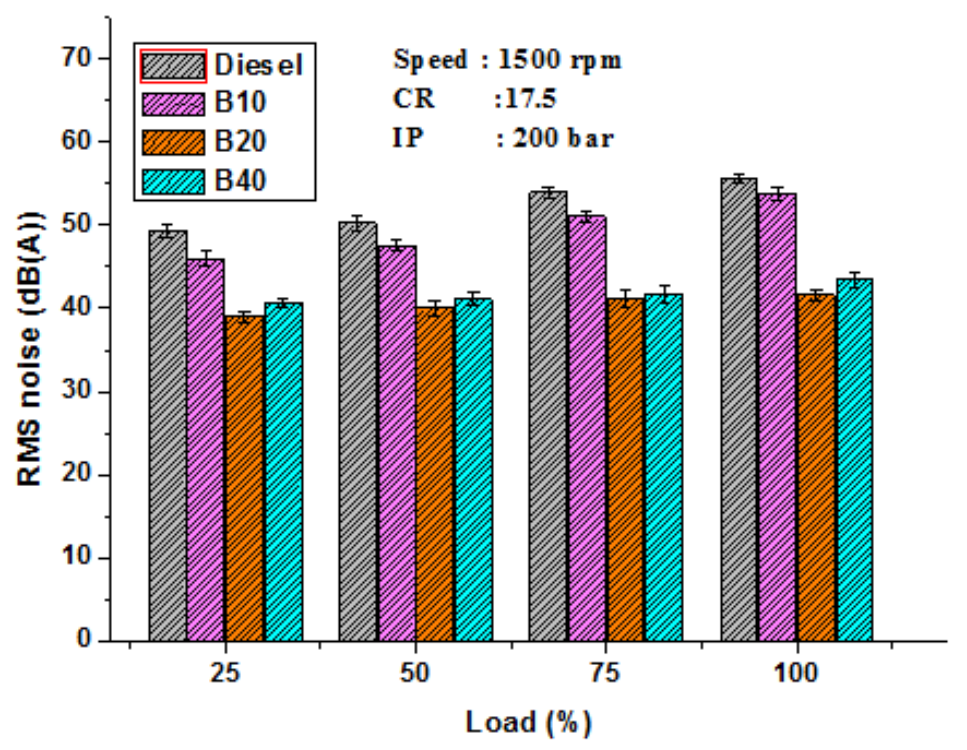

Figure 9. RMS noise at different loads.

The RMS value of noise for conventional diesel, B10, B20, and B40 was about 55.68525549 $\mathrm{dB}(\mathrm{A}), 53.83839575 \mathrm{~dB}(\mathrm{~A}), 41.60468024 \mathrm{~dB}(\mathrm{~A})$, and $43.45433219 \mathrm{~dB}$ (A) respectively at $100 \%$ load.

\section{CONCLUSIONS}

The following conclusions were made from this investigation:

- $\quad$ The properties of NSOME blends are within the ASTM range.

- $\quad$ The CO, UHC emissions, and smoke opacity were reduced for B10, B20, and B40 when compared against diesel. Nevertheless, there was a mild up surge in NOx level with NSOME blends.

- $\quad$ Slightest emission values of CO, UHC, and smoke opacity were observed with B20 than remaining test fuel blends. But the NOx was observed lowered for diesel fuel only. The similar observation was made at all the load conditions and the increasing trend was followed towards the rising load. At maximum load, the decrease in $\mathrm{CO}$, UHC, and smoke opacity of B20 were $93.9 \%, 37.87 \%$, and $5.54 \%$ respectively and $\mathrm{NO}_{\mathrm{x}}$ increment was $12.76 \%$ in opposition to diesel.

- $\quad$ Further, theRMS velocity and RMS noise of B10, B20, and B40 were lowered than diesel at all the load conditions from lowest to highest load. However, the RMS velocity and RMS noise of the entire test fuels were improved towards the maximum load. 
- $\quad$ The RMS velocity and RMS noise of B20 have depicted lower value than remaining blends of test fuels.

- $\quad$ For B20 blend, the vibration and noise levels were decreased by $45.78 \%$ and $26.15 \%$ respectively as compared to diesel.

Pertaining to above conclusions, B20 could be the possible replacement in the VCR diesel engine devoid of any adjustments. Further, the studies could be performed by altering the injection operating pressure to assess the emissions, vibrations, and noise parameters.

\section{REFERENCES}

[1] Senthil R, Silambarasan, R, Pranesh,G. Performance improvement and exhaust emissions reduction in biodiesel operated diesel engine through the use of operating parameters and catalytic converter: A review. Renewable and Sustainable Energy Reviews 2018; 81: 3215-3222

[2] Liu H, Wang Z, Wang J, He X. Improvement of emission characteristics and thermal efficiency in diesel engines by fueling gasoline/diesel/PODEn blends. Energy 2016; 97:105-112.

[3] Chen Z, Yao C, Wang Q, Han G, Dou Z, Wei H. Study of cylinder-to-cylinder variation in a diesel engine fueled with diesel/methanol dual fuel. Fuel 2016; 170: 6776.

[4] Cheikh K, Sary A, Khaled L, Abdelkrim L,Mohand T. Experimental assessment of performance and emissions maps for biodiesel fueled compression ignition engine. Applied Energy 2016; 161:320-329.

[5] Ankur N, Biswajit P, Sunil K.S. Comparison of performance and emissions characteristics of CI engine fuelled with dual biodiesel blends of palm and jatropha. Fuel 2016; 173: 172-179.

[6] Taghizadeh AA, Ghobadian B, Tavakoli HT, Mohtasebi S, Saeid S, Mohtasebi S. Vibration analysis of a diesel engine using biodiesel and petro-diesel fuel blends. Fuel 2012; 102:.414-422.

[7] Ahmad TA, Abbas RA. The effect of added ethanol to diesel fuel on performance, vibration, combustion and knocking of a CI engine. Fuel 2016; 185:718-733.

[8] Franz HFA.Time-frequency analysis: concepts and methods. 1st ed. ISTE Ltd. and John Wiley \& Sons, Inc.; 2008.

[9] Hadi T, Shahram K, Samad J. Diesel engine spray characteristics prediction with hybridized artificial neural network optimized by genetic algorithm. Energy 2014; 71:656-664.

[10] Erinc U, Yildizhan, Kadir A, Mustafa O. Vibration, noise and exhaust emissions analysis of an unmodified compression ignition engine fueled with low sulphur diesel and biodiesel blends with hydrogen addition. International Journal of Hydrogen Energy 2016; 41:11481-490.

[11] Chiatti G, Chiavola O, Palmieri F. Vibration and acoustic characteristics of a city car engine fueled with biodiesel blends. Applied Energy 2017; 185(1):664-670.

[12] Jaikumar S, Bhatti S K, Srinivas V. Experimental investigations on performance, combustion, and emission characteristics of Niger (Guizotiaabyssinica) seed oil 
Methyl Ester Blends with diesel at different compression ratios. Arabian Journal of Science and Engineering 2019; 44: 5263-5273.

[13] Vijayaraj K, Sathiyagnanam A P. Experimental investigation of a diesel engine with methyl ester of mango seed oil and diesel blends. Alexandria Engineering Journal 2016; 55:215-221.

[14] Senthur NS, Ravikumar TS. An experimental investigation on performance, combustion and emission parameters biodiesel-water emulsion on a DI diesel engine. International Journal of Engineering Sciences and Research Technology 2016; 5(8): 54-62

[15] How HG, Masjuki HH, Kalam MA, Teoh YH. An investigation of the engine performance, emissions and combustion characteristics of coconut biodiesel in a high pressure common-rail diesel engine. Energy 2014; 69:749-759.

[16] Zhi CO, Mohd BMM, Wen TC, Roon SS,Hwai CO, Zubaidah I. Identification of optimum Calophylluminophyllum bio-fuel blend in diesel engine using advanced vibration analysis technique. Renewable Energy 2017; 109:295-304.

[17] Heidary B, Hasaan B, Ghobadian B, Taghizadeh A. Vibration analysis of small diesel engine using diesel biodiesel blends. Agricultural Engineering International: CIGR Journal 2013; 15:117-126.

[18] Uludamar E, Tosun E, Aydın K. Experimental and regression analysis of noise and vibration of a compression ignition engine fuelled with various biodiesels. Fuel 2016; 177:326-333.

[19] Zhen D, Tesfa B, Yuan X, Wang R, Gu F, Ball AD. An investigation of the acoustic characteristics of a compression ignition engine operating with biodiesel blends. Journal of Physics: Conference Series 2012; 364: 012-015.

[20] Sanjid A, Masjuki HH, Kalam MA, Ashrafur RSM, Abedin MJ, Palash SM. Production of palm and jatropha based biodiesel and investigation of palm jatropha combined blend properties, performance, exhaust emission and noise in an unmodified diesel engine. Journal Cleaner Production 2014; 65:295-303.

[21] Jaikumar S, Bhatti SK, Srinivas V, Rajasekhar M. Vibration and noise characteristics of CI engine fueled with Niger seed oil methyl ester blends and hydrogen. International Journal of Engineering Science and Technology. Article in press. 2019.

[22] Bhaskar K, Sendilvelan S. Experimental studies on the performance and emission characteristics of a compression ignition engine fuelled with jatropha oil methyl ester. Journal of Mechanical Engineering and Sciences 2018; 12 (1):3431-3450.

[23] Bhaskar, K, Sendilvelan, S, Muthu, V, Aravindraj S. Performance and emission characteristics of compression ignition engine using methyl ester blends of jatropha and fish oil. Journal of Mechanical Engineering and Sciences 2016; 10:1994-2007

[24] Buyukkaya E. Effects of biodiesel on a DI diesel engine performance, emission and combustion characteristics. Fuel 2010; 89:3099-3105.

[25] Yasin MHM, Mamat R, Aziz A, Yusop AF, Ali MH. Investigation of Combustion parameters of palm biodiesel operating with a diesel engine. Journal of Mechanical Engineering and Sciences 2015; 9: 1714-1726.

[26] Dong Z, Zhanqun S, Zhongyue S, Fengshou G, Andrew B.Combustion Noise Analysis for Combustion and Fuels Diagnosis of a CI Diesel Engine Operating with Biodiesels. Journal of Combustion Science and Technology 2015; 187 (12): 1974-1992. 